\title{
Metabotropic glutamate receptor 3 protects neurons from glucose-induced oxidative injury by increasing intracellular glutathione concentration
}

\author{
Alison Berent-Spillson* and James W. Russell*,†† \\ *Neuroscience Program, University of Michigan, Ann Arbor, Michigan, USA \\ $\dagger$ Veterans Affairs Medical Center, Baltimore, Maryland, USA \\ $\$$ Department of Neurology, University of Maryland, Baltimore, Maryland, USA
}

\begin{abstract}
High glucose concentrations cause oxidative injury and programmed cell death in neurons, and can lead to diabetic neuropathy. Activating the type 3 metabotropic glutamate receptor (mGluR3) prevents glucose-induced oxidative injury in dorsal root ganglion neurons co-cultured with Schwann cells. To determine the mechanisms of protection, studies were performed in rat dorsal root ganglion neuron-Schwann cell co-cultures. The mGluR3 agonist 2R,4R-4-aminopyrrolidine-2,4-dicarboxylate prevented glucose-induced inner mitochondrial membrane depolarization, reactive oxygen species accumulation, and programmed cell death, and increased glutathione (GSH) concentration in co-cultured neurons and Schwann cells, but not in neurons cultured without Schwann cells. Protection was
\end{abstract}

diminished in neurons treated with the GSH synthesis inhibitor L-buthionine-sulfoximine, suggesting that mGluR-mediated protection requires GSH synthesis. GSH precursors and the GSH precursor GSH-ethyl ester also protected neurons from glucose-induced injury, indicating that GSH synthesis in Schwann cells, and transport of reaction precursors to neurons, may underlie mGluR-mediated neuroprotection. These results support the conclusions that activating glial mGluR3 protects neurons from glucose-induced oxidative injury by increasing free radical scavenging and stabilizing mitochondrial function, through increased GSH antioxidant defense.

Keywords: diabetic neuropathy, glutathione, metabotropic glutamate receptor, oxidative stress, Schwann cell. J. Neurochem. (2007) 101, 342-354.
Peripheral sensory neuropathy occurs in at least 50\% of diabetic subjects (Dyck et al. 1993). The cause of diabetic neuropathy remains unknown, although oxidative stress has been implicated (Cameron et al. 1993; Nagamatsu et al. 1995; Hohman et al. 1997; Low et al. 1997; Tomlinson 1998; Stevens et al. 2000; Obrosova 2002; Russell et al. 2002; Schmeichel et al. 2003). Following a high-glucose load, reactive oxygen species (ROS) formation increases due to metabolic flux in the mitochondria. Increased ROS expression is associated with membrane lipid peroxidation, protein nitration, inner mitochondrial membrane potential $\left(\Delta \Psi_{\mathrm{M}}\right)$ changes, ballooning of mitochondria, and DNA degradation (Sasaki et al. 1997; Fujimura et al. 1999; Russell et al. 1999, 2002; Kishi et al. 2002; Huang et al. 2003; Allen et al. 2005). This oxidative damage is associated with further neuronal injury, as well as injury to Schwann cells, and can initiate programmed cell death (PCD) (Delaney et al. 2001; Berent-Spillson et al. 2004; Cowell and Russell 2004; Allen et al. 2005; Niedowicz and Daleke 2005).
Received June 12, 2006; revised manuscript received October 3, 2006; accepted October 5, 2006.

Address correspondence and reprint requests to James W. Russell, Department of Neurology, University of Maryland School of Medicine, 22 South Greene Street, Baltimore, MD 21201-1595, USA.

E-mail: jruss@umich.edu

Abbreviations used: APDC, 2R,4R-4-aminopyrrolidine-2,4-dicarboxylate (specific metabotropic glutamate receptor 3 agonist); BSO, buthionine sulfoximine (GSH synthesis inhibitor); caspase, cysteinerequiring aspartate protease; CysGly, cysteinylglycine (GSH degradation product); DAPI, 4'-6-diamidino-2-phenylindole; DCF, dichlorodihydrofluorescein; DCFDA, 5-(and 6)-chloromethyl-2', $7^{\prime}$-dichlorodihydrofluorescein diacetate, acetyl ester; DHE, dihydroethidium; DRG, dorsal root ganglion; FCCP, carbonyl cyanide 4-(trifluoromethoxy)phenylhydrazone (electron transport uncoupler); GCP II/III, glutamate carboxypeptidase II/III; GSH, glutathione; GSH-EE, glutathione ethyl ester; GST, glutathione-s-transferase; $\mathrm{H}_{2} \mathrm{O}_{2}$, hydrogen peroxide; HBSS, Hank's balanced salt solution; JC-1, 5,5',6,6'-tetrachloro-1,1',3,3'-tetraethylbenzimidazolylcarbocyanine iodide; MCB, monochlorobimane; mGluR, metabotropic glutamate receptor; NAAG, $N$-acetyl-aspartyl-glutamate; PBS, phosphate-buffered saline; PCD, programmed cell death; Rh123, rhodamine123; ROS, reactive oxygen species; $\Delta \Psi_{\mathrm{M}}$, inner mitochondrial membrane potential. 
Oxidative stress is a central pathogenic mechanism in the development and progression of diabetic neuropathy. Oxidative injury under high-glucose conditions is associated with destabilization of the $\Delta \Psi_{\mathrm{M}}$, mitochondrial permeability transition, adenine nucleotide translocase/voltage-dependent anion channel opening, and cytochrome $c$ translocation from the mitochondria into the cytosol, resulting in PCD (Russell et al. 2002). Destabilization of the $\Delta \Psi_{\mathrm{M}}$ promotes production of superoxides (superoxide anion), increased flux through the mitochondrial electron transport chain, and facilitates production of other radical species and radical precursors, including hydrogen peroxide $\left(\mathrm{H}_{2} \mathrm{O}_{2}\right)$ and hydroxyl radicals $\left(\mathrm{OH}^{-}\right)$. ROS deplete antioxidant defenses, including glutathione (GSH), and can alter antioxidant enzyme activity, affecting availability of GSH peroxidase and reductase, catalase, and superoxide dismutase (Vincent et al. 2004b). In the diabetic rat, measures of oxidative stress and reduced levels of circulating antioxidants parallel neuropathy, and blocking oxidative stress in the diabetic animal prevents the development of neuropathy (for review, see Vincent et al. 2004b; Niedowicz and Daleke 2005; Russell and Kaminsky 2005). Dorsal root ganglion (DRG) neurons are particularly susceptible to glucose-mediated oxidative stress, partly due to their exceptional metabolic energy requirements. Excessive glucose concentration, mimicking that of untreated diabetes, causes mitochondrial dysfunction and PCD in cultured DRG neurons.

Induction of oxidative stress is associated with increased ROS expression and decreased regulation of $\Delta \Psi_{\mathrm{M}}$. Conversely, increased free radical scavenging and stabilization of the $\Delta \Psi_{\mathrm{M}}$ can prevent oxidative injury (Brownlee 2001; Russell et al. 2002; Vincent et al. 2002, 2004a). Activating the type 3 metabotropic glutamate receptor (mGluR3) protects neurons from injury or death in several nervous system pathologies (Maiese et al. 2000; Pizzi et al. 2000; Thomas et al. 2001; Yao et al. 2005; Zhong et al. 2005), and receptor-mediated neuroprotection requires glial-neuronal interaction (Bruno et al. 1997; Thomas et al. 2001; Yao et al. 2005). The mGluRs are a family of 8 G-proteincoupled glutamate receptors, subdivided into three groups based on function and sequence. As a member of group II, mGluR3 regulates neuronal signaling from glial and presynaptic locations throughout the central and peripheral nervous systems (Cartmell and Schoepp 2000; De Blasi et al. 2001). We previously demonstrated that activating mGluR3 prevents glucose-induced neuronal injury in a cell culture model of diabetic neuropathy, and that protection in this model requires interaction between DRG neurons and Schwann cells (Berent-Spillson et al. 2004).

The link between oxidative stress and glucose-induced neuronal injury is established and is a key factor in the pathogenesis of diabetic neuropathy. However, regulation of oxidative injury is still poorly understood. The current study examines the mechanism of mGluR3 regulation of oxidative injury in a DRG neuron-Schwann cell co-culture system, and establishes a novel link between mGluR3 neuroprotection and GSH antioxidant defense.

\section{Materials and methods}

\section{Materials}

Cell culture materials and reagents

Sprague-Dawley rats (Harlan-Sprague Dawley, Indianapolis, IN, USA); B-27, neurobasal medium (Invitrogen, Carlsbad, CA, USA); nerve growth factor (Harlan Bioproducts for Science, Indianapolis, IN, USA); trypsin, pen/strep/neo, L-glutamine, 5-fluoro-2-deoxyuridine, fetal bovine serum (Sigma-Aldrich, St Louis, MO, USA).

\section{Treatment reagents}

D-glucose, buthionine sulfoximine (BSO), $\gamma$-glutamyl cysteine (GEC), cysteinylglycine (CysGly), GSH ethyl ester (GSH-EE), GSH, valinomycin, carbonyl cyanide 4-(trifluoromethoxy)phenylhydrazone (FCCP) were from Sigma-Aldrich. Group II mGluR agonist $\quad(2 R, 4 R)$-4-aminopyrrolidine-2,4-dicarboxylate (APDC) (Tocris Cookson Inc., Ellisville, MO, USA). APDC has specificity for group II mGluRs over other mGluRs $\left(\mathrm{EC}_{50}\right.$ of $0.4 \mu \mathrm{mol} / \mathrm{L}$ for mGluRs 2 and 3, vs. 100, 100, 300, and $300 \mu \mathrm{mol} / \mathrm{L}$ for mGluR1, mGluR5, mGluR4, and mGluR7, respectively) (Schoepp et al. 1999).

\section{Oxidative stress/PCD analysis reagents}

Bovine serum albumin (Jackson ImmunoResearch, West Grove, PA, USA); normal goat serum (Vector Laboratories, Burlingame, CA, USA); Triton X-100 (Sigma-Aldrich); rabbit polyclonal cleaved cysteine-requiring aspartate protease (caspase)-3 antibody (Cell Signaling Technology, Inc., Beverly, MA, USA); Alexafluor 594 goat anti-rabbit antibody, highly cross-adsorbed, Hank's balanced salt solution (HBSS) (Invitrogen); dihydroethidium (DHE), 5-(and 6)-chloromethyl-2', $7^{\prime}$-dichlorodihydrofluorescein diacetate, acetyl ester (DCFDA), 5,5',6,6'-tetrachloro-1,1',3,3'-tetraethylbenzimidazolylcarbocyanine iodide (JC-1), rhodamine123 (Rh123), 4'-6-diamidino-2-phenylindole (DAPI) (Invitrogen); monochlorobimane (MCB) (Sigma-Aldrich).

Neuron-Schwann cell co-culture and pure neuronal culture Pure DRG neuronal cultures and DRG neuron-Schwann cell co-cultures were prepared as described previously except that Schwann cells were not removed from co-cultures (Russell et al. 1999, 2002; Vincent et al. 2002). Dissociated DRG cultures from 15-day-old embryonic (E15) Sprague-Dawley rats were prepared by incubating whole DRG in $0.25 \%$ trypsin for $30 \mathrm{~min}$ at $37^{\circ} \mathrm{C}$, centrifuging at $800 \mathrm{~g}$ for $5 \mathrm{~min}$, and then removing trypsin. Cultures were grown for 5 days on collagen-coated glass coverslips in neurobasal medium containing $25 \mathrm{mmol} / \mathrm{L}$ glucose (optimal basal glucose for neurons) (Russell and Feldman 1999; Russell et al. 1999; Srinivasan et al. 2000), with $0.5 \%$ B27, $10 \mathrm{ng} / \mathrm{mL}$ nerve growth factor, $0.5 \% \mathrm{Pen} / \mathrm{Strep} / \mathrm{Neo}$, and $0.14 \mathrm{mmol} / \mathrm{L} \mathrm{L-glutamine}$. The medium for pure neuronal cultures also contained $40 \mu \mathrm{mol} / \mathrm{L}$ 5-fluoro-2-deoxyuridine. Media was changed every $48 \mathrm{~h}$, and immediately before drug treatment. During experimental drug 
treatment, all cells were treated in $25 \mathrm{mmol} / \mathrm{L}$ glucose, unless exposed to elevated glucose concentrations $(20 \mathrm{mmol} / \mathrm{L}$ added glucose; $45 \mathrm{mmol} / \mathrm{L}$ total glucose), as indicated. All animal procedures and experiments were approved by and performed in accordance with the University of Michigan Committee on Use and Care of Animals and the Veterans Affairs Research and Development committee.

\section{ROS detection}

\section{DCFDA}

Upon oxidation and removal of acetate groups, cell permeant DCFDA is visible as the fluorescent dichlorodihydrofluorescein (DCF), and detects $\mathrm{H}_{2} \mathrm{O}_{2}$, hydroxyl radical, alkylperoxyl and hydroperoxyl radicals, and peroxynitrite anion. Immediately after each experimental timepoint, cultures were rinsed with HBSS, and further incubated with $2.5 \mu \mathrm{mol} / \mathrm{L}$ DCFDA in HBSS for $15 \mathrm{~min}$ at $37^{\circ} \mathrm{C}$. Cells were rinsed once with phosphate-buffered saline (PBS) then fixed for 30 min with $4 \%$ paraformaldehyde in PBS. Samples were then co-stained in $1 \mu \mathrm{g} / \mathrm{mL}$ DAPI in PBS for $5 \mathrm{~min}$ at $20^{\circ} \mathrm{C}$, to allow DRG and Schwann cell nuclei to be separately identified, and then mounted on slides with Biomedia Gel/Mount. Some samples also underwent immunocytochemistry for cleaved caspase3 prior to DAPI co-stain. Slides were analyzed at $60 \times$ magnification on an Olympus Fluoview Confocal microscope (Olympus Corporation, Center Valley, PA, USA) by a blinded observer. Optimal microscope and camera settings were determined, and left constant throughout the entire experiment. For each slide, images from 10 random fields of 25-100 cells per field were collected in brightfield and fluorescent channels. DCF pixel intensity was determined for each neuron using ImageJ software (Opensource Software; NIH, Bethesda, MD, USA), mean pixel intensity for each field of neurons calculated, and background intensity subtracted. Mean pixel intensities were averaged for each condition. In order to make comparisons between separate experiments, data are expressed as percent of control, where control equals 100 .

\section{DHE}

Dihydroethidium detects superoxide anion, fluorescing red when oxidized to ethidium. After each experimental timepoint, samples were rinsed with HBSS, and incubated with $1 \mu \mathrm{g} / \mathrm{mL}$ DHE in HBSS for $20 \mathrm{~min}$ at $37^{\circ} \mathrm{C}$. Samples were then rinsed with HBSS, and livecell images were immediately collected on a Zeiss Axiovert inverted microscope (Carl Zeiss, Inc., Thornwick, NY, USA). Images were collected in brightfield and fluorescent channels for 10 fields per sample. Optimal camera and microscope settings were determined, and remained constant throughout the entire experiment. Fluorescent pixel intensity was determined for each neuron using ImageJ software, and the mean pixel intensity for each field was calculated after subtracting background. Mean values were averaged for each condition, and expressed in arbitrary units.

\section{Mitochondrial membrane potential measurement}

$J C-1$

Fluorescent emission of cationic JC-1 changes from red to green as the $\Delta \Psi_{\mathrm{M}}$ depolarizes, and was used to compare mitochondrial membrane polarity between treatment conditions. Immediately after each experimental timepoint, cells were rinsed with HBSS, and incubated with $2 \mu \mathrm{g} / \mathrm{mL} \mathrm{JC}-1$ in HBSS for $15 \mathrm{~min}$ at $37^{\circ} \mathrm{C}$. Cells were then rinsed with HBSS, and live-cell images were immediately collected on a Zeiss Axiovert inverted microscope. Ten images per sample were collected in green- and red-fluorescent ranges. Mean pixel intensities for both channels were determined for each neuron using ImageJ software, and averaged for each field. Mean background intensity was determined for both channels in each field by averaging three pixel intensity measurements of non-cell areas, and then subtracted from the average neuron pixel intensity for each field. For each field, ratio of green to red fluorescence was calculated, and field ratios were averaged for each condition, and expressed in arbitrary units. For each experiment, results were compared with the inner mitochondrial membrane depolarization controls valinomycin or FCCP $(2 \mu \mathrm{mol} / \mathrm{L}$ added concurrently with JC-1 only).

\section{Rhodamine 123}

Rhodamine123 accumulates in live mitochondria in a potentialdependent fashion, allowing for comparison of mitochondrial membrane polarity to be made between treatment conditions. After each experimental timepoint, cells were rinsed with HBSS, and incubated with $5 \mathrm{mg} / \mathrm{mL}$ of Rh123 in HBSS for $10 \mathrm{~min}$ at $37^{\circ} \mathrm{C}$. Samples were rinsed again with HBSS, then live-cell images were immediately collected on a Zeiss Axiovert inverted microscope. Images from 10 fields per sample were collected, in brightfield and fluorescent channels. The mean pixel intensity for each neuron was calculated, averaged for each field, and background intensity subtracted. Mean pixel intensities for each field were averaged for each condition. For each experiment, results were compared with cells treated with the membrane-depolarizing controls valinomycin, or FCCP $(2 \mu \mathrm{mol} / \mathrm{L}$ added concurrently with Rh123 only), and expressed in arbitrary units.

\section{Immunocytochemistry for cleaved caspase-3}

Cultures were fixed after the experimental timepoint for $30 \mathrm{~min}$ with $4 \%$ paraformaldehyde in PBS, and then stained for active caspase-3 as described previously (Russell et al. 1999, 2002; Vincent et al. 2002). Cultures were incubated with rabbit polyclonal cleaved caspase- 3 antibody overnight at $4{ }^{\circ} \mathrm{C}$, at a $1: 500$ dilution in PBS with $1 \%$ bovine serum albumin, $1 \%$ normal goat serum, and $0.1 \%$ Triton X 100 . Cells were rinsed $3 \times 10 \mathrm{~m}$ in PBS, and then incubated with $5 \mu \mathrm{g} / \mathrm{mL}$ Alexafluor 596 goat-anti-rabbit antibody at $20^{\circ} \mathrm{C}$ for $1 \mathrm{~h}$. Specificity and concentration of the antiactive antibody was determined by immunoadsorption against cleaved peptide. Samples were then co-stained with $1 \mu \mathrm{g} / \mathrm{mL}$ DAPI in PBS for $5 \mathrm{~min}$ at $20^{\circ} \mathrm{C}$. The DAPI permits DRG and Schwann cell nuclei to be easily and separately identified. Cells were mounted on slides with Biomedia Gel/Mount (Electron Microscopy Sciences, Hatfield, PA, USA), and analyzed at $60 \times$ magnification on an Olympus Fluoview Confocal microscope by a blinded observer. For each slide, images from 10 arbitrary fields of 25-100 cells per field were collected, and the percentage of caspase-3positive neurons was determined for each field. The percentages for each field were averaged for each condition. Caspase- 3 activity was detected by pixel intensity measurement using ImageJ software. Cells with caspase-3 pixel intensity over a specific threshold, which was determined for each experiment, were considered to be positive 
for caspase-3 cleavage. This method provides greater sensitivity of detection than visual assessment.

\section{GSH detection}

Intracellular GSH concentration was determined in DRG neurons and Schwann cells using MCB. MCB binds to GSH through interaction with glutathione-s-transferase (GST) to form a stable fluorescent adduct (MCB-GSH), allowing measurement of intracellular GSH concentration through fluorescent intensity of the MCB-GSH adduct. MCB has more selectivity for GSH over other thiols when compared with other bimanes, including monobromobimane, and was confirmed to react only with GSH in hepatocytes by HPLC (Fernandez-Checa and Kaplowitz 1990). Comparison of GSH concentration was performed between treatment groups using a method slightly modified from previous descriptions (Chatterjee et al. 1999; Keelan et al. 2001; Sebastia et al. 2003). Immediately after the experimental timepoint, cultures were rinsed with HBSS, and further incubated with $60 \mu \mathrm{mol} / \mathrm{L} \mathrm{MCB}$ in $0.1 \%$ dimethyl sulfoxide in HBSS for $20 \mathrm{~min}$ at $37^{\circ} \mathrm{C}$. Cells were rinsed with PBS, then fixed for 30 min with $4 \%$ paraformaldehyde in PBS before mounting on slides. Fluorescent images were collected at $60 \times$ magnification on an Olympus Fluoview Confocal microscope by a blinded observer. For each slide, images from 10 random fields of 25-100 cells per field were collected. Mean pixel intensity for each cell was calculated, and mean values calculated after subtracting background intensity. Neurons and Schwann cells were analyzed separately.

\section{Statistical analysis}

Normal distribution was confirmed for each data set. Overall changes in measures were analyzed using ANOVA, and individual comparisons were carried out using Student's $t$-test, assuming unequal variances. Levels of significance were determined from a two-tailed $t$-test, with comparisons made to control, except where otherwise noted. For graphical and descriptive purposes, data are presented as mean \pm SEM. Each experiment was repeated at least two times.

\section{Results}

Activating mGluR3 decreases glucose-induced oxidative injury and stabilizes the $\Delta \Psi_{\mathrm{M}}$

Similar to previously published results, a time-course analysis revealed that peak oxidative injury in DRG neuron-Schwann cell co-cultures occurred after $24 \mathrm{~h}$ of exposure to $20 \mathrm{mmol} / \mathrm{L}$ added glucose $(45 \mathrm{mmol} / \mathrm{L}$ total glucose) (Berent-Spillson et al. 2004). At 24 hours of glucose exposure in co-cultures, caspase-3 cleavage occurred in a mean of $27.0 \pm 5.7 \%$ of neurons, compared with $5.7 \pm 0.9 \%$ of neurons not treated with elevated glucose, $18.3 \pm 4.8 \%$ of neurons treated with elevated glucose for $3 \mathrm{~h}$, and $19.9 \pm 7.0 \%$ of neurons at $6 \mathrm{~h}$ of glucose treatment. Similarly, no significant change in ROS expression was detected until $24 \mathrm{~h}$ of elevated glucose treatment. At 3 and $6 \mathrm{~h}$ of glucose treatment, ROS expression was not statistically different than control, with mean DCF fluorescent intensities of $107 \pm 7.5 \%$ and $112 \pm 5.9 \%$ of control, respectively. At $24 \mathrm{~h}$, mean DCF fluorescent intensity was $140 \pm 12.7 \%$ of control. The peak timepoint of $24 \mathrm{~h}$ of glucose treatment was used for further experiments, as described below.

The next series of experiments determined that the mGluR3 agonist APDC reversed oxidative injury caused by elevated glucose concentration in DRG neurons cocultured with Schwann cells (Fig. 1). The ROS expression was measured with the free radical probes DCF (Fig. 1a) and DHE (Fig. 1b). At $24 \mathrm{~h}$ of elevated glucose concentrations, there was an increase in ROS expression, and $100 \mu \mathrm{mol} / \mathrm{L}$ APDC prevented this glucose-induced ROS accumulation. We also observed that cells treated with APDC alone (no glucose) showed less ROS expression than untreated control cells. This effect is probably due to mGluR3-mediated prevention of basal levels of oxidative injury observed in cultured cells (Halliwell 2003). The prevention of oxidative injury corresponded temporally with PCD inhibition, as determined by caspase-3-positive neurons (Fig. 1c).

We next determined the effect of elevated glucose and mGluR3 activation on mitochondrial function. Elevated glucose concentrations, associated with increased ROS expression, causes mitochondrial membrane hyperpolarization, followed by depolarization, then PCD. We found that neurons co-cultured with Schwann cells and treated with $20 \mathrm{mmol} / \mathrm{L}$ added glucose exhibited inner mitochondrial membrane depolarization at $24 \mathrm{~h}$, detected by JC-1 and Rh123 (Fig. 2). Glucose-induced changes in the $\Delta \Psi_{M}$ were prevented by concurrent treatment with $100 \mu \mathrm{mol} / \mathrm{L}$ APDC, suggesting that mGluR3-mediated neuroprotection may be associated with reduced oxidative stress at the mitochondria and improved mitochondrial function. APDC alone had no effect on the $\Delta \Psi_{\mathrm{M}}$. The observed effects of APDC on the $\Delta \Psi_{\mathrm{M}}$ are consistent with the concept that mGluR3 agonists reduce oxidative injury and initiation of PCD in DRG neurons.

\section{mGluR3 activation increases intracellular GSH concentration}

Decreased ROS expression can be due to reduced production, or to increased free radical scavenging. To determine if mGluR3 activation decreases ROS activity by increasing antioxidant free radical scavenging, we examined the effect of APDC on GSH concentration in co-cultured DRG neurons and Schwann cells. Cells were treated with increasing concentrations of APDC (100-500 $\mu \mathrm{mol} / \mathrm{L})$ for 24 hours, and the relative GSH concentration was determined by quantifying fluorescent intensity of the MCB-GSH adduct (Fig. 3). In neurons (Fig. 3a) and Schwann cells (Fig. 3b), receptor activation was positively correlated with increasing GSH concentration, consistent with an increase in GSH synthesis. The specificity of MCB for GSH was determined using the GSH analog GSH-EE and the GSH synthesis 
(a)

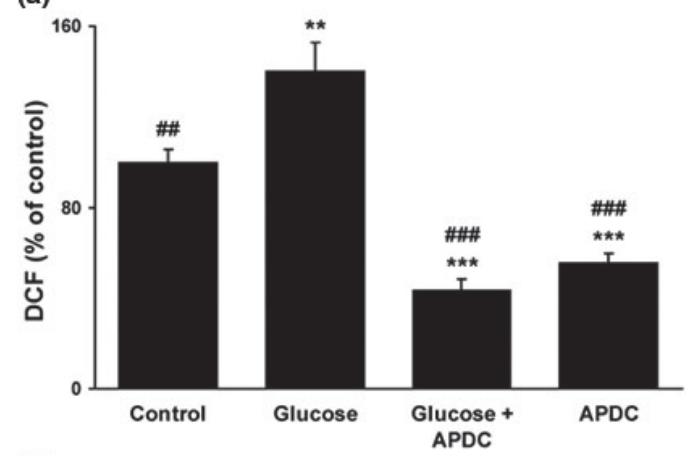

(b)

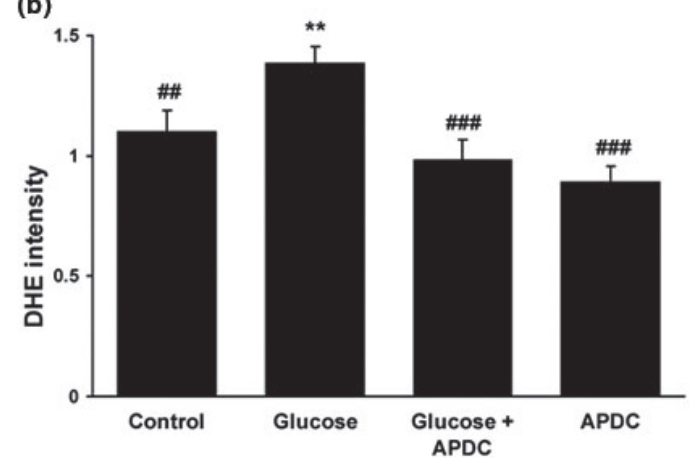

(c)

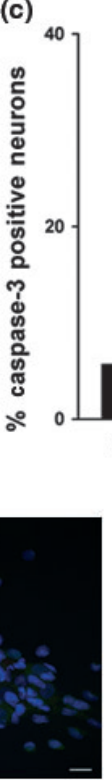

(d)
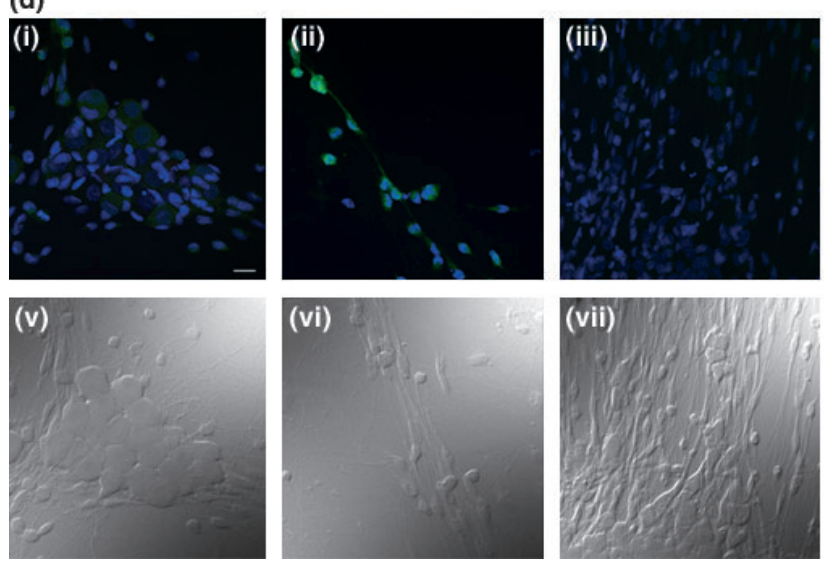
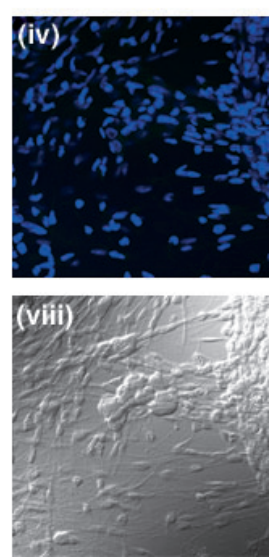

Fig. $12 R, 4 R$-4-Aminopyrrolidine-2,4-dicarboxylate (APDC) prevents glucoseinduced oxidative injury. Rat embryo dorsal root ganglion neurons co-cultured with endogenous Schwann cells were treated for $24 \mathrm{~h} \pm 20 \mathrm{mmol} / \mathrm{L}$ added glucose \pm $100 \mu \mathrm{mol} / \mathrm{L}$ APDC, then assessed for programmed cell death or reactive oxygen species (ROS) expression. (a) Intracellular ROS expression, determined by relative dichlorodihydrofluorescein fluorescent intensity (expressed as percent of control). Measurements are from paraformaldehydefixed cells. (b) Intracellular ROS expression, determined by dihydroethidium fluorescent intensity (expressed in arbitrary units). Measurements are from live-cell fluorescent images. (c) Percentage of neurons undergoing programmed cell death, detected by immunocytochemistry for cleaved caspase3. Data are expressed as mean \pm SEM. ${ }^{\star} p<0.05 ;{ }^{\star *} p<0.01 ;{ }^{* \star *} p<0.001$ versus control; \# $p<0.05$; ${ }^{\# \#} p<0.01$; \#\#\# $p<0.001$ versus $20 \mathrm{mmol} / \mathrm{L}$ added glucose. (d) Fluorescent confocal images of co-cultured dorsal root ganglion neurons and Schwann cells expressing ROS, as detected with dichlorodihydrofluorescein (green) (panels i-iv) or brightfield (panels v-viii). Nuclei are stained with 4'-6-diamidino-2-phenylindole for visualization purposes (blue). Cells treated for $24 \mathrm{~h}$, as follows: control (panels $\mathrm{i}$ and $\mathrm{v}$ ), $20 \mathrm{mmol} / \mathrm{L}$ glucose (panels ii and vi), $20 \mathrm{mmol} / \mathrm{L}$ glucose $+100 \mu \mathrm{mol} / \mathrm{L}$ APDC (panels iii and vii), and $100 \mu \mathrm{mol} / \mathrm{L}$ APDC (panels iv and viii). Scale bar $=100 \mu \mathrm{m}$. inhibitor BSO. The MCB-GSH intensity in co-cultured DRG neurons treated with $200 \mu \mathrm{mol} / \mathrm{L}$ GSH-EE for $24 \mathrm{~h}$ was $118 \pm 2.0 \%$ of control, and those treated with $10 \mu \mathrm{mol} / \mathrm{L}$
BSO had a MCB-GSH intensity of $11.5 \pm 0.4 \%$ of control. The MCB-GSH intensity in co-cultured Schwann cells treated with $200 \mu \mathrm{mol} / \mathrm{L}$ GSH-EE for $24 \mathrm{~h}$ was $128 \pm 2.5 \%$ 
(a)

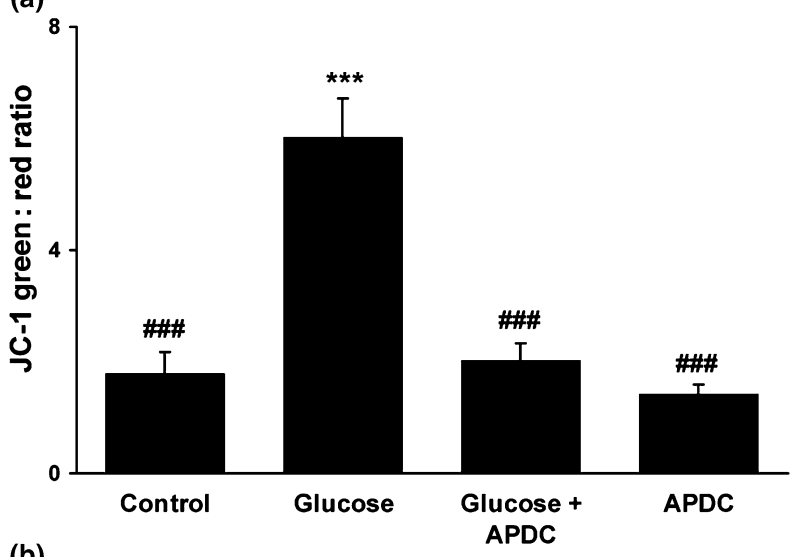

(b)

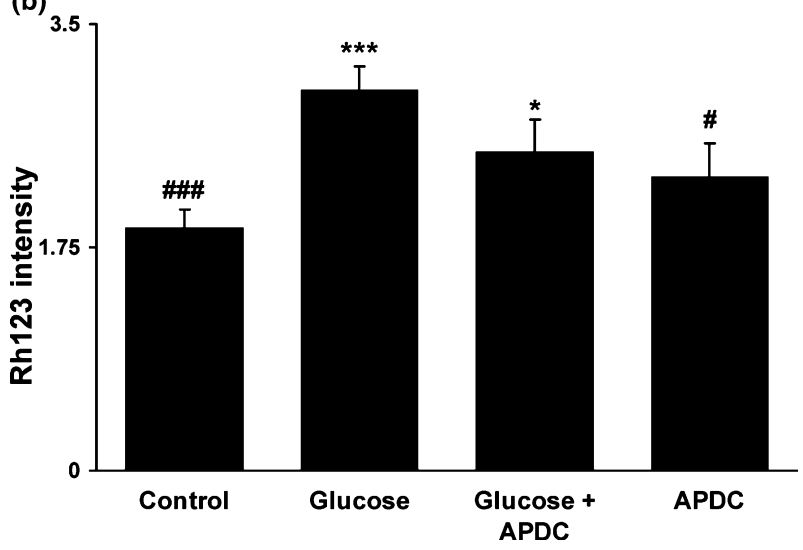

Fig. 2 2R,4R-4-Aminopyrrolidine-2,4-dicarboxylate (APDC) prevents glucose-induced mitochondrial membrane depolarization. Rat embryo dorsal root ganglion neurons co-cultured with endogenous Schwann cells were treated for $24 \mathrm{~h} \pm 20 \mathrm{mmol} / \mathrm{L}$ added glucose $\pm 100 \mu \mathrm{mol} / \mathrm{L}$ 2R,4R-4-aminopyrrolidine-2,4-dicarboxylate, then membrane polarity was determined in live cells. (a) Mitochondrial membrane polarity, determined by the ratio of green to red $5,5^{\prime}, 6,6^{\prime}$-tetrachloro-1, $1^{\prime}, 3,3^{\prime}$ tetraethylbenzimidazolylcarbocyanine iodide fluorescent intensity. (b) Mitochondrial membrane potential, determined by whole-cell rhodamine123 fluorescent intensity (expressed in arbitrary units). Data are expressed as mean \pm SEM. ${ }^{*} p<0.05 ;{ }^{* *} p<0.01$; ${ }^{\star \star *} p<0.001$ versus control; ${ }^{\#} p<0.05 ;{ }^{\# \#} p<0.01 ;{ }^{\# \# \#} p<0.001$ versus $20 \mathrm{mmol} / \mathrm{L}$ added glucose. In each experiment, cells treated with a depolarization control [valinomycin or carbonyl cyanide 4-(trifluoromethoxy)phenylhydrazone] showed greater depolarization than did glucose-treated cells.

of control, and those treated in $10 \mu \mathrm{mol} / \mathrm{L}$ BSO had a MCBGSH intensity of $12.5 \pm 0.8 \%$ of control.

mGluR3-mediated GSH increase requires Schwann cells We previously showed that mGluR3-mediated protection from glucose-induced PCD does not occur in neurons cultured without Schwann cells (Berent-Spillson et al. 2004). To determine that the mGluR3-mediated increase in relative GSH concentration requires Schwann cells, and if this phenomenon is related to neuroprotection, we examined (a)

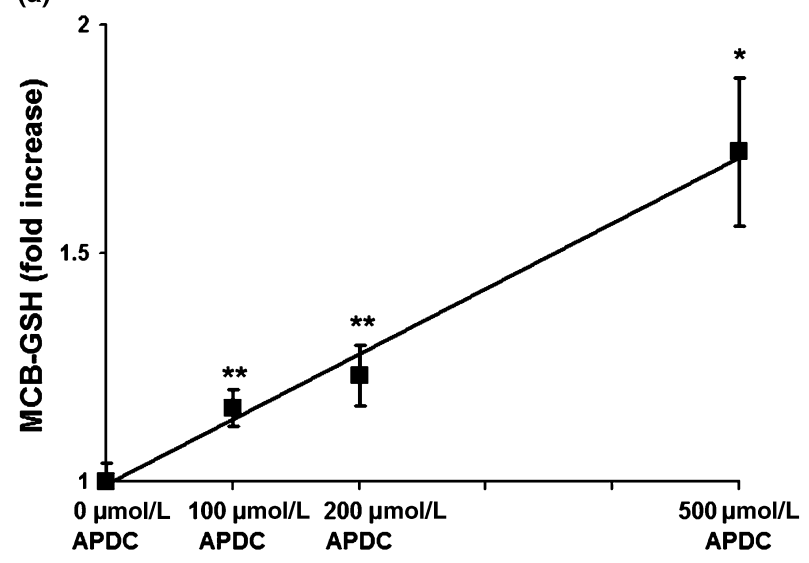

(b)

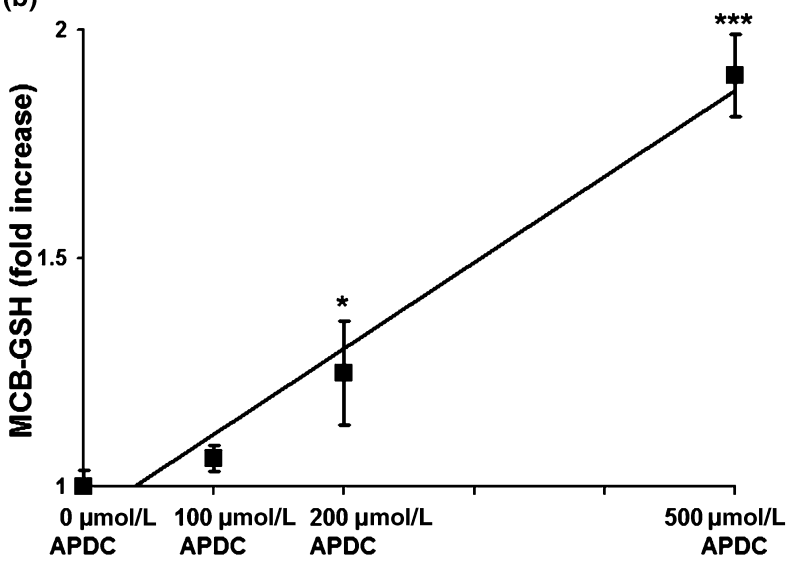

(c)

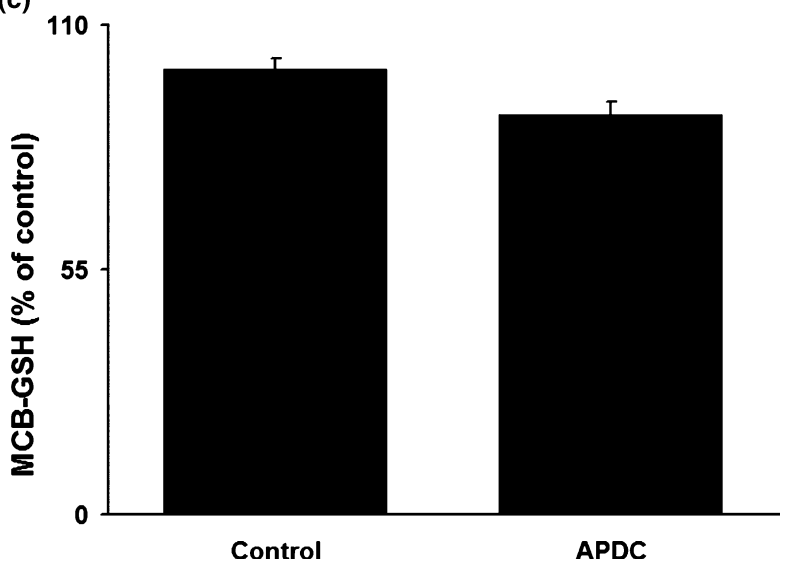

Fig. $32 R, 4 R$-4-Aminopyrrolidine-2,4-dicarboxylate (APDC) treatment stimulates glutathione (GSH) synthesis in co-cultured dorsal root ganglion neurons (a) and Schwann cells (b), but not in pure-cultured neurons grown without Schwann cells (c). Cells were treated with 0 , 100,200 , or $500 \mu \mathrm{mol} / \mathrm{L}$ APDC for $24 \mathrm{~h}$, then incubated with monochlorobimane for $20 \mathrm{~min}$ before paraformaldehyde fixation. Relative GSH concentration was determined by fluorescent intensity of the monochlorobimane-GSH adduct individually in each cell type. Data are expressed as fold increase over control ( $a$ and $b$ ) or percent of control (c) (mean \pm SEM). ${ }^{\star} p<0.05 ;{ }^{* \star} p<0.01$; ${ }^{* \star *} p<0.001$ versus $0 \mu \mathrm{mol} / \mathrm{L}$ APDC. Linear trend lines have $R^{2}$ values of 0.9896 (a) and $0.9762(b)$ 
the effect of the mGluR3 agonist APDC on GSH concentration on DRG neurons cultured without Schwann cells (Fig. 3c). In pure-cultured DRG neurons, activating mGluR3 does not change GSH concentration relative to non-treated neurons, indicating that Schwann cells are required for this effect.

High glucose decreases GSH concentration in co-cultured DRG neurons and Schwann cells, and mGluR3 activation increases GSH in the presence of elevated glucose concentrations

A 24-h incubation in elevated glucose concentrations decreases fluorescent MCB-GSH intensity in co-cultured DRG neurons and Schwann cells (Fig. 4). This decrease in

(a)

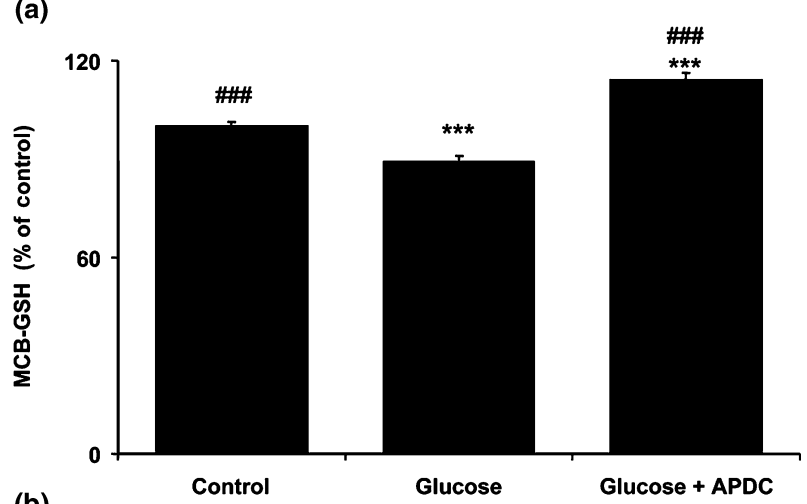

(b)

Control

Glucose

Glucose + APDC

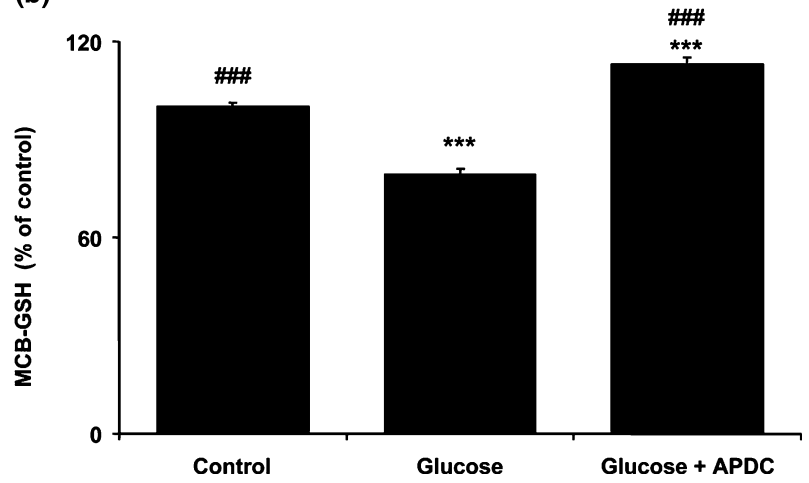

Fig. 4 High-glucose treatment decreases glutathione (GSH) concentration in co-cultured dorsal root ganglion neurons (a) and Schwann cells (b), and type 3 metabotropic glutamate receptor activation increases GSH in the presence of elevated glucose concentrations. Rat embryo dorsal root ganglion neurons co-cultured with endogenous Schwann cells were treated with control $(25 \mathrm{mmol} / \mathrm{L})$ or elevated $(45 \mathrm{mmol} / \mathrm{L})$ glucose concentrations for $24 \mathrm{~h}, \pm 100 \mu \mathrm{mol} / \mathrm{L}$ of the type 3 metabotropic glutamate receptor agonist $2 R, 4 R$-4-aminopyrrolidine-2,4-dicarboxylate, then incubated with monochlorobimane for $20 \mathrm{~min}$ before paraformaldehyde fixation. Relative $\mathrm{GSH}$ concentration was determined by fluorescent intensity of the monochlorobimane-GSH adduct individually in each cell type. Data are expressed as percent of control (mean \pm SEM). ${ }^{*} p<0.05 ;{ }^{* *} p<0.01$; ${ }^{\star * *} p<0.001$ versus control and ${ }^{\#} p<0.05 ;{ }^{\# \#} p<0.01 ;{ }^{\# \# \#} p<0.001$ versus $20 \mathrm{mmol} / \mathrm{L}$ added glucose.
GSH concentration was reversed by concurrent incubation with the specific mGluR3 agonist APDC; mGluR3 agonist increased GSH concentrations over those of control, indicating that increased GSH concentration in the presence of high glucose may account for neuroprotective effects of mGluR3 activation.

Inhibiting GSH synthesis increases oxidative injury and prevents mGluR3-mediated neuroprotection

The previous results suggest that mGluR3 activation increases GSH antioxidant defense systems, but do not confirm that receptor-mediated protection is mediated through this response. To determine if protection requires increased GSH synthesis, we examined protective properties in conditions of GSH-synthesis inhibition.

\section{Inhibiting GSH synthesis increases glucose-induced oxidative injury}

We initially explored the effects of inhibiting GSH synthesis in our DRG neuron-Schwann cell co-culture system (Figs 5 and 6). We found that the GSH synthesis inhibitor BSO, which prevents the synthesis of GSH synthesis intermediate $\gamma$-glutamylcysteine (GGC), causes dose-dependent changes in measures of oxidative injury in co-cultured DRG neurons. Treatment with 10 or $100 \mu \mathrm{mol} / \mathrm{L}$ BSO resulted in significant mitochondrial membrane depolarization and caspase- 3 cleavage at $24 \mathrm{~h}$ (Fig. 5).

While depleting cells of GSH itself causes oxidative damage, BSO also increases susceptibility to glucoseinduced oxidative injury (Fig. 6). Cells treated with $10 \mu \mathrm{mol} / \mathrm{L}$ BSO for $24 \mathrm{~h}$ exhibited caspase-3 cleavage that increased with the duration of exposure to added glucose. Neurons treated with elevated glucose for $3 \mathrm{~h}$ had significantly more caspase- 3 cleavage than those treated with glucose alone, and maximal caspase- 3 cleavage was reached by $6 \mathrm{~h}$ of concurrent BSO and glucose treatment. By $24 \mathrm{~h}$ of concurrent treatment, the percent of caspase-3-positive neurons had dropped to $<5 \%$, and morphologic observation confirmed that nearly all neurons were dead at this timepoint.

\section{APDC neuroprotection requires $G S H$}

An increase in GSH concentration may result from de novo synthesis through the $\gamma$-glutamyl cycle, or from increased recycling of glutathione disulfide, as well as through decreased GSH breakdown. To determine if mGluR3-mediated protection requires de novo GSH synthesis, we examined the effects of APDC on glucose-treated cells in the presence of the GSH synthesis inhibitor BSO. DRGSchwann cell co-cultures were pre-treated with $10 \mu \mathrm{mol} / \mathrm{L}$ BSO for $20 \mathrm{~h}$, and then treated with BSO for additional $3 \mathrm{~h}$, with or without glucose and APDC. APDC was unable to prevent glucose-induced PCD (Fig. 7). These data suggest that the neuroprotective effects of mGluR3 activation are 


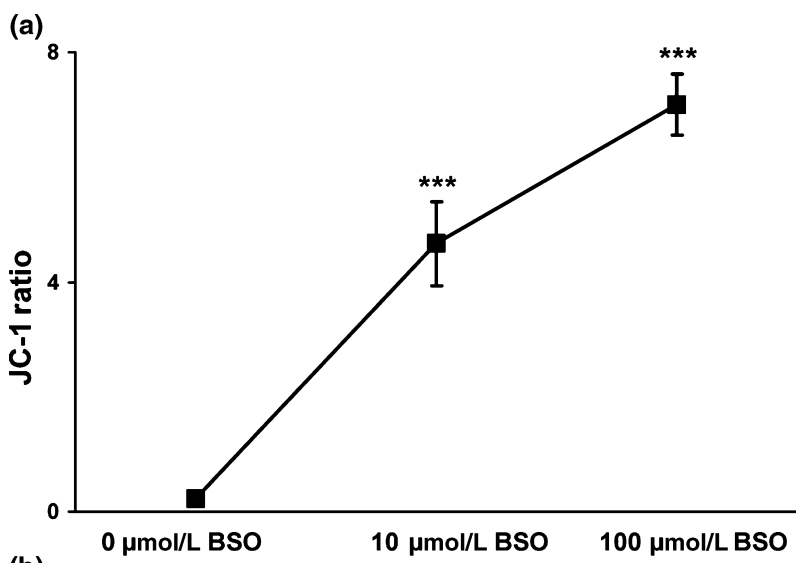

(b)

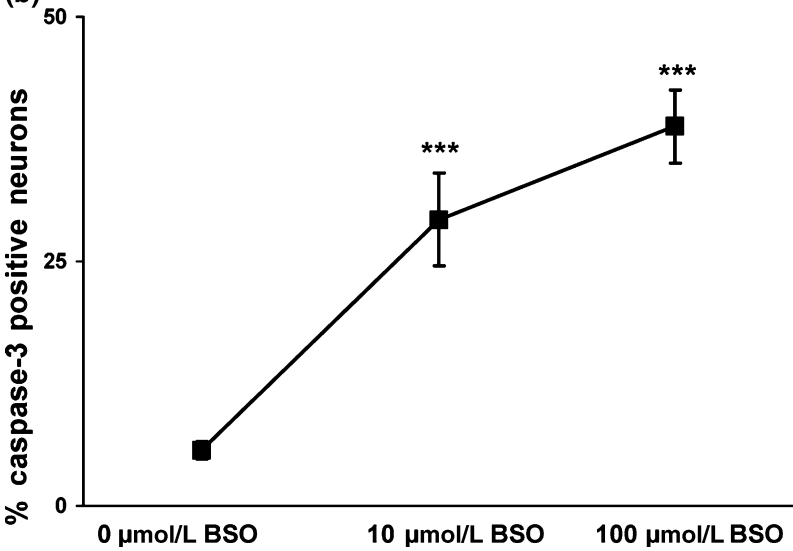

Fig. 5 Inhibiting glutathione synthesis causes mitochondrial injury and neuronal death. Rat embryo dorsal root ganglion neurons cocultured with endogenous Schwann cells were treated with 0,10 or $100 \mu \mathrm{mol} / \mathrm{L}$ of the glutathione synthesis inhibitor buthionine sulfoximine for $24 \mathrm{~h}$, then assessed for programmed cell death or reactive oxygen species expression. (a) Mitochondrial membrane potential, detected by ratio of green to red $5,5^{\prime}, 6,6^{\prime}$-tetrachloro-1, $1^{\prime}, 3,3^{\prime}$-tetraethylbenzimidazolylcarbocyanine iodide fluorescent intensity (b) Percent of neurons undergoing programmed cell death, detected by immunocytochemistry for cleaved caspase-3. Data are expressed as mean \pm SEM. ${ }^{\star} p<0.05 ;{ }^{\star \star} p<0.01 ;{ }^{* \star \star} p<0.001$ versus $0 \mu \mathrm{mol} / \mathrm{L}$ buthionine sulfoximine.

mediated through increased GSH antioxidant production and subsequent decrease in oxidative stress.

\section{Neuroprotection and oxidative stress by GSH or GSH synthesis precursor}

Increasing GSH concentration exogenously prevents glucose-induced oxidative injury, but can also cause oxidative damage in control neurons. DRG neurons co-cultured with endogenous Schwann cells were treated with GSH or GSH synthesis precursor, with or without $20 \mathrm{mmol} / \mathrm{L}$ added glucose, and assessed for ROS expression and caspase-3 cleavage (Fig. 8). At a 24-h timepoint, GSH-EE and $\gamma$-glutamylcysteine both prevented ROS accumulation and

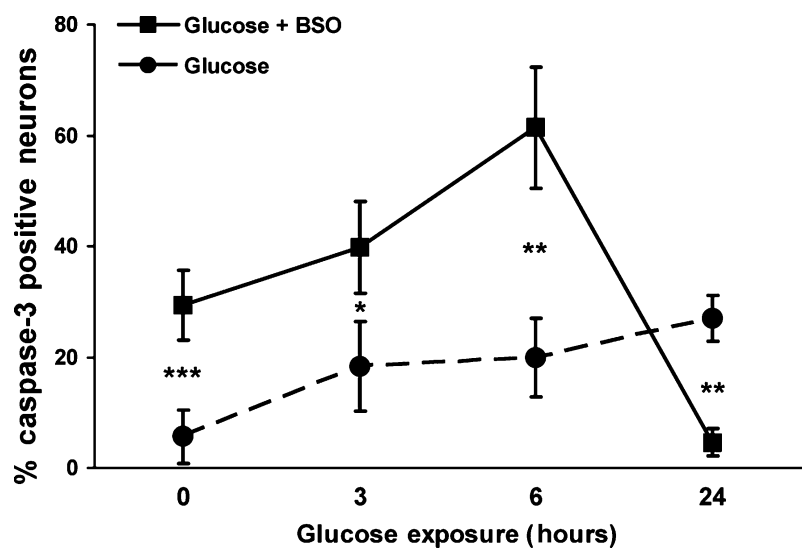

Fig. 6 Inhibiting glutathione synthesis increases susceptibility to glucose-induced cell death. Rat embryo dorsal root ganglion neurons co-cultured with endogenous Schwann cells were treated for $24 \mathrm{~h}$ with $10 \mu \mathrm{mol} / \mathrm{L}$ of the glutathione synthesis inhibitor buthionine sulfoximine $\pm 0,3,6$, or $24 \mathrm{~h}$ of concurrent $20 \mathrm{mmol} / \mathrm{L}$ added glucose (solid line), or with glucose alone (dashed line). Percent of cells undergoing programmed cell death was determined by immunocytochemistry for cleaved caspase-3. Data are expressed as mean \pm SEM. ${ }^{*} p<0.05$; ${ }^{\star *} p<0.01 ;{ }^{* \star *} p<0.001$, with comparison cells treated with or without buthionine sulfoximine at each glucose timepoint.

PCD in the presence of elevated glucose concentrations, but caused oxidative injury in normal glucose conditions. Similar to these observations, the GSH degradation product CysGly protected neurons from glucose-induced ROS accumulation, but when applied at normal glucose concentrations, CysGly increased DCF intensity (data not shown; DCF intensity was $145 \pm 28.4 \%$ of control in cells treated with $10 \mu \mathrm{mol} / \mathrm{L}$ CysGly for $24 \mathrm{~h}$, and DCF intensity was $85.3 \pm 22.5 \%$ of control in cells treated with $10 \mu \mathrm{mol} / \mathrm{L}$ CysGly $\pm 20 \mathrm{mmol} / \mathrm{L}$ glucose for $24 \mathrm{~h}$ ). For each reagent tested, a dose-response curve was determined, and the dosage that provided optimal neuroprotection was selected for further experiments.

\section{Discussion}

In this study, we show that activating mGluR3 prevents glucose-induced oxidative damage to DRG neurons, including ROS accumulation, mitochondrial membrane depolarization, and PCD. Activating mGluR3 increases GSH concentrations in co-cultured neurons and Schwann cells, and the increased antioxidant defense and free radical scavenging may be responsible for mGluR3-mediated protection from glucose-induced oxidative effects.

We found that the mGluR3 agonist APDC prevented ROS accumulation, mitochondrial membrane depolarization, and PCD in co-cultured DRG neurons exposed to elevated glucose concentration. These results indicate that mGluR3 activation protects neurons by regulating mitochondrial stability and reducing ROS-mediated oxidative stress, 


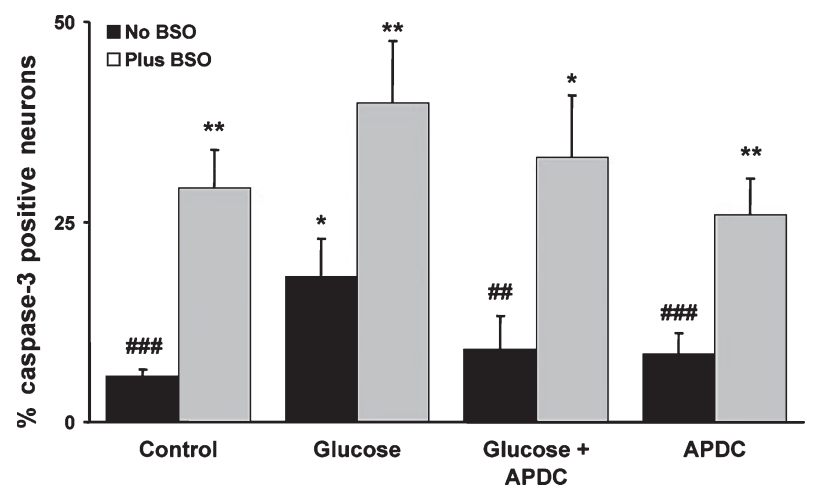

Fig. 7 2R,4R-4-Aminopyrrolidine-2,4-dicarboxylate neuroprotection requires glutathione synthesis. Rat embryo dorsal root ganglion neurons co-cultured with endogenous Schwann cells were pre-treated in control media (black bars) or with $10 \mu \mathrm{mol} / \mathrm{L}$ of the glutathione synthesis inhibitor buthionine sulfoximine (BSO) (gray bars) for $20 \mathrm{~h}$, then incubated for $3 \mathrm{~h} \pm 20 \mathrm{mmol} / \mathrm{L}$ added glucose $\pm 100 \mu \mathrm{mol} / \mathrm{L} 2 R, 4 R-4$ aminopyrrolidine-2,4-dicarboxylate. Percent of cells undergoing programmed cell death was determined by immunocytochemistry for cleaved caspase-3. Data are expressed as percent of control (mean $\pm \mathrm{SEM}$ ). ${ }^{*} p<0.05 ;{ }^{* *} p<0.01 ;{ }^{* \star *} p<0.001$ versus control (no BSO); $" p<0.05 ;{ }^{\# \#} p<0.01 ;{ }^{\# \#} p<0.001$ versus $20 \mathrm{mmol} / \mathrm{L}$ added glucose (no BSO).

subsequently preventing initiation of cell death pathways. Evidence supports these events as critical in mGluR3 prevention of oxidative injury: mGluR activation prevents neuronal injury, including glucose-induced neuronal injury (Vincent and Maiese 2000; De Blasi et al. 2001; BerentSpillson et al. 2004). Previous studies show that glutamate carboxypeptidase II (GCP II) inhibitors protects neurons by increasing levels of the endogenous mGluR3 agonist $\mathrm{N}$ acetyl-aspartyl-glutamate (NAAG) (Wroblewska et al. 1993, 1997; Thomas et al. 2000, 2003). Previous evidence from our laboratory found that both NAAG and GCP II/III inhibitor 2-(phosphonomethyl)pentanedioic acid prevent glucose-induced PCD and neurite degeneration in DRG neurons (Berent-Spillson et al. 2004), and further evidence from preclinical studies demonstrates that GCP II/III inhibitors prevent diabetic neuropathy in an animal model (Zhang et al. 2002). This evidence suggests that mGluR 3 in particular is critical to neuroprotection, as there is no evidence of NAAG activity at mGluR2; however, APDC has activity at mGluR2 as well as mGluR3, and it is possible that mGluR2 activation is also neuroprotective. The current study shows that the mGluR3 agonist APDC prevents oxidative injury. Together these findings are consistent with the concept that mGluRs prevent cellular injury by regulating oxidative stress in the neuron. However, the mechanism of mGluR3 protection from ROS-induced oxidative injury remains to be elucidated.

The observation that mGluR activation prevents oxidative injury suggests that neuroprotection may be mediated through endogenous antioxidant systems (Vincent et al.
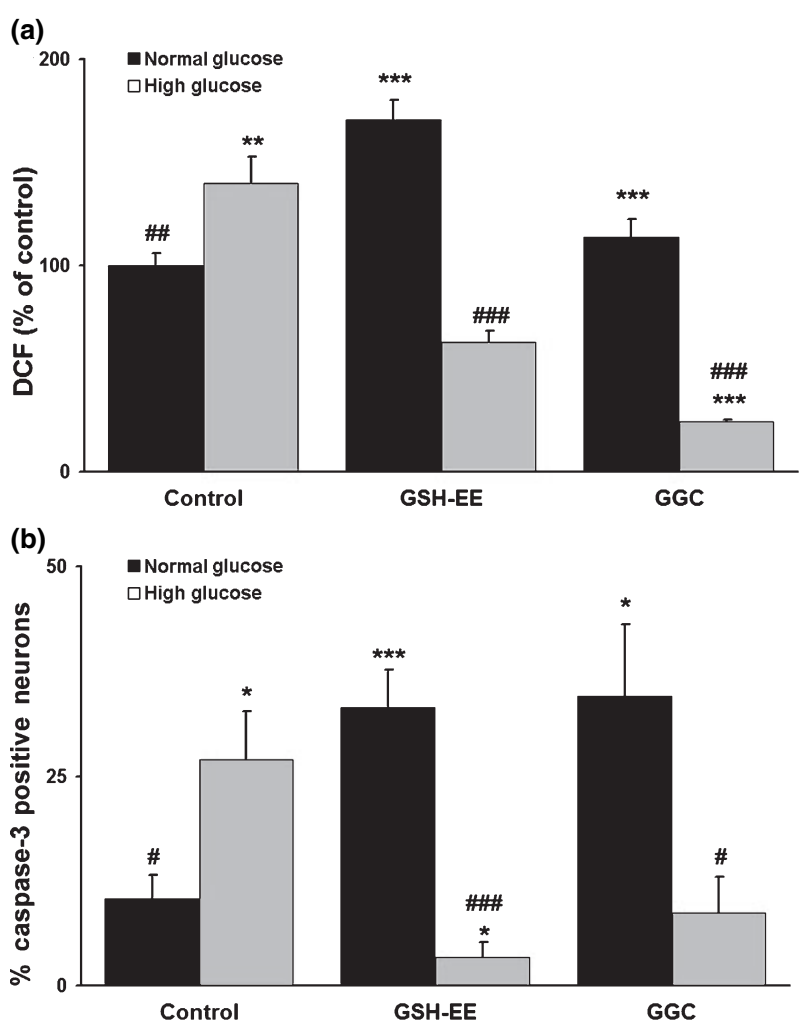

Fig. 8 Glutathione-ethyl ester (GSH-EE) and $\gamma$-glutamylcysteine (GGC) are neuroprotective in high-glucose conditions, but induce oxidative injury at normal glucose concentration. Oxidative injury was assessed in rat embryo dorsal root ganglion neurons co-cultured with endogenous Schwann cells after $24 \mathrm{~h}$ of treatment with $200 \mu \mathrm{mol} / \mathrm{L}$ of the GSH analog GSH-EE or $100 \mu \mathrm{mol} / \mathrm{L}$ of the GSH synthesis intermediate GGC, at normal glucose concentration (black bars) or in $20 \mathrm{mmol} / \mathrm{L}$ added glucose (gray bars). (a) Intracellular reactive oxygen species expression, determined by relative dichlorodihydrofluorescein fluorescent intensity (expressed as percent of control). (b) Percent of neurons undergoing programmed cell death, detected by immunocytochemistry for cleaved caspase-3. Data are expressed as mean \pm SEM. ${ }^{*} p<0.05 ;{ }^{* *} p<0.01 ;{ }^{* * *} p<0.001$ versus control; $\# p<0.05 ; " \# p<0.01 ; " \# \#<0.001$ versus $20 \mathrm{mmol} / \mathrm{L}$ added glucose.

1997; Maiese and Vincent 1999; Lin and Maiese 2001; Deng et al. 2004). GSH, in particular, is a critical regulator of ROS activity and cellular redox balance, and is one of the most important intracellular free radical scavengers in mammalian cells. GSH has many functions, but in particular the thiol moiety is a potent reducing agent both in neurons and glia (Vincent et al. 2004b; Ghezzi et al. 2005). GSH levels are higher in glial cells than neuronal cells, and it has been suggested that glia are critical to maintaining antioxidant defense in neurons (Sagara et al. 1993; Rice and RussoMenna 1998; Dringen et al. 1999, 2000; Gegg et al. 2005). Recent studies found that diabetic humans and animals have lower concentrations of GSH, and less GSH turnover than non-diabetic controls (van Dam et al. 2001; Maritim et al. 
2003; Gil-del Valle et al. 2005). Similarly, high glucose concentration has been found to reduce GSH in cultured Schwann cells (Suzuki et al. 2004). We confirmed this result in Schwann cells, and also found that high glucose lowers GSH in DRG neurons co-cultured with Schwann cells. The mGluR3 agonist APDC increased GSH concentrations in the presence of elevated glucose, in both DRG neurons and Schwann cells, supporting our hypothesis that activating mGluR3 prevents glucose-induced oxidative injury. Additionally, we found that depleting cellular GSH in DRG neuron-Schwann cell co-cultures by inhibiting GSH synthesis can itself be a source of oxidative stress to the cell, causing mitochondrial membrane depolarization, ROS accumulation, and PCD. Neurons depleted of GSH showed an increased oxidative response to elevated glucose concentration, and oxidative injury occurred at an earlier timepoint than in neurons treated with glucose or BSO alone. These results are consistent with a decrease in GSH concentration contributing to the glucose-mediated oxidative effects in diabetic neuropathy.

In the CNS, mGluR3 regulates directional flow of the $\mathrm{X}_{\mathrm{C}}{ }^{-}$ glutamate-cystine antiporter system, with receptor activation mediating cystine influx, likely through the moderation of protein kinase A activity (Baker et al. 2002; Xi et al. 2002; Tang and Kalivas 2003; Melendez et al. 2005; Moran et al. 2005; Yao et al. 2005). Increased intracellular cystine through this system occurs predominantly in glial cells, where the majority of mGluR3 receptors are located, and may facilitate the formation of cysteine, a rate-limiting reaction precursor for GSH synthesis through the $\gamma$-glutamyl cycle. This suggests a role for GSH antioxidant defense in mGluR3-mediated protection. Our results support this hypothesis; intracellular GSH concentration is increased in both DRG neurons and Schwann cells after a 24-h incubation in APDC. However, increased GSH may not result from this pathway of de novo synthesis, and this result could indicate increased recycling from glutathione disulfide, although it is unlikely that large changes in GSH concentration would result from this pathway. To address this point, we determined that protection does not occur when de novo synthesis is inhibited with BSO, suggesting that mGluR3mediated protection utilizes increased GSH synthesis.

Glutathione deficiency may be partly responsible for oxidative neuronal damage in diabetic patients (van Dam et al. 1995, 1998, 1999, 2001; Nagamatsu et al. 1995; Tachi et al. 1998; Stevens et al. 2000; Suzuki et al. 2004; Gil-del Valle et al. 2005). We determined that cells depleted of GSH did exhibit signs of oxidative stress, and were more susceptible to toxic effects of glucose than non-GSHdepleted controls. The mGluR3 activation did not protect cells from oxidative damage caused by GSH depletion, whether or not glucose concentration was elevated, providing further evidence that receptor-mediated protection depends on GSH and GSH synthesis. This increase is dose dependent in both cell types; however, APDC causes a greater increase in GSH concentration in Schwann cells than in neurons, especially at the neuroprotective lower doses. This observation indicates the active role of Schwann cells in providing neuroprotection through increased GSH concentrations.

It should be noted that MCB reacts with GSH through interaction with GST. Another possible explanation for increased MCB-GSH with increasing dose of APDC is that APDC increases GST activity, rather than GSH concentration. However, the specificity of MCB for GSH, determined by increased MCB-GSH with GSH-EE treatment and decreased MCB-GSH with BSO treatment, suggest that MCB-GSH intensity is correlated with intracellular GSH concentration, rather than other factors such as GST activity or inhibition of conjugate export. It is also possible that the observed neuroprotective effects are due to interaction between APDC and glutamate-interacting enzymes other than the mGluRs, possibly including those involved in GSH synthesis. However, this scenario is unlikely, as we have previously demonstrated a complete abolition of mGluR3mediated neuroprotective and anti-oxidative effects with an mGluR3-specific antagonist (Berent Spillson and Russell 2003; Berent-Spillson et al. 2004). Additionally, there is currently no evidence that APDC interacts with substrates other than the group II mGluRs; however, the possibility cannot be completely excluded and has not been examined in detail.

We previously established that mGluR3-mediated neuroprotection requires the presence of Schwann cells, indicating a need for glial-neuronal interactions (Berent-Spillson et al. 2004). In the current study, we found that activating mGluR3 increases GSH concentration in Schwann cells and in neurons co-cultured with Schwann cells, but does not affect GSH concentration in neurons cultured without Schwann cells. This supports the hypothesis that activating mGluR3 located on Schwann cells increases neuronal GSH, through increased GSH synthesis in Schwann cells and transport of GSH or GSH synthesis precursors to neurons. This is further supported by the discovery that the GSH analog GSH-EE, the GSH synthesis intermediate $\gamma$-glutamylcysteine, and the GSH degradation product CysGly each protect DRG neurons from glucose-induced oxidative effects. An unexpected result, however, is that these agents themselves caused significant oxidative damage in normal glucose conditions. A possible explanation for the pro-PCD effect of these antioxidants is that they may be reacting with components of the cell culture media extracellularly to form $\mathrm{H}_{2} \mathrm{O}_{2}$, as has been documented for GSH, $\gamma$-glutamylcysteine, $\mathrm{N}$-acetylcysteine, and CysGly (Hua Long and Halliwell 2001). This effect is unlikely in our system due to the disparity of the response in high versus normal glucose-treated cells, and also to the observation that exogenous GSH, which is not as readily transported into neurons as GSH-EE, did not induce PCD in normal glucose-treated cells, and was not 
neuroprotective to high-glucose cells, indicating that it was not transported by neurons (data not shown). It is more likely that the difference in effect is caused by altered oxidation states in normal versus high-glucose-treated cells; glucose alters antioxidant activity and redox cycling in cultured cells as well as diabetic subjects (van Dam et al. 1995, 1998, 1999, 2001; Nagamatsu et al. 1995; Tachi et al. 1998; Stevens et al. 2000; Suzuki et al. 2004; Gil-del Valle et al. 2005). Without sufficient redox cycling, excess antioxidants may become toxic if allowed to accumulate in their reduced state, and it has been noted that antioxidants can cause cellular injury and death, depending on the oxidation state of the cell (Halliwell 2000). This caveat suggests a significant benefit for neuropathy treatment options that increase endogenous antioxidant defense systems, rather than the addition of exogenous antioxidants.

In conclusion, we found that activating mGluR3 on DRG neurons co-cultured with endogenous Schwann cells prevented high glucose-induced oxidative injury, including ROS accumulation and mitochondrial membrane depolarization, and increased GSH concentration in both neurons and Schwann cells. High-glucose conditions caused oxidative injury, and decreased GSH concentration. Activating mGluR3 increased GSH in the presence of elevated glucose, and neuroprotection was diminished when GSH synthesis was inhibited, suggesting that mGluR3-mediated neuroprotection utilizes increased GSH to counter glucose-induced oxidative injury. Together these findings are consistent with the emerging concept that mGluRs prevent neuronal injury by regulating oxidative stress, and implicate increased GSH antioxidant defense as a primary mechanism of protection. By increasing endogenous antioxidant defense systems, mGluR3 agonists may represent a novel mechanism to prevent ROS-induced PCD in diabetic neuropathy.

\section{Acknowledgements}

We would like to thank Ms Denice Janus for secretarial support. This work was supported in part by NIH NS42056, The Juvenile Diabetes Research Foundation Center for the Study of Complications in Diabetes (JDRF), Office of Research Development (Medical Research Service), Department of Veterans Affairs (JWR), NIDDK no. 5P60DK-20572, the Michigan Diabetes Research and Training Center (MDRTC), and the Michigan Imaging Laboratory.

\section{References}

Allen D. A., Yaqoob M. M. and Harwood S. M. (2005) Mechanisms of high glucose-induced apoptosis and its relationship to diabetic complications. J. Nutr. Biochem. 16, 705-713.

Baker D. A., Xi Z. X., Shen H., Swanson C. J. and Kalivas P. W. (2002) The origin and neuronal function of in vivo nonsynaptic glutamate. J. Neurosci. 22, 9134-9141.

Berent Spillson A. and Russell J. W. (2003) Metabotropic glutamate receptor regulation of neuronal cell death. Exp. Neurol. 184, S97S105.
Berent-Spillson A., Robinson A., Golovoy D., Slusher B., Rojas C. and Russell J. W. (2004) Protection against glucose-induced neuronal death by NAAG and GCP II inhibition is regulated by mGluR3. J. Neurochem. 89, 90-99.

Brownlee M. (2001) Biochemistry and molecular cell biology of diabetic complications. Nature 414, 813-820.

Bruno V., Sureda F. X., Storto M., Casabona G., Caruso A., Knopfel T., Kuhn R. and Nicoletti F. (1997) The neuroprotective activity of group-II metabotropic glutamate receptors requires new protein synthesis and involves a glial-neuronal signaling. J. Neurosci. 17, 1891-1897.

Cameron N. E., Cotter M. A. and Maxfield E. K. (1993) Anti-oxidant treatment prevents the development of peripheral nerve dysfunction in streptozotocin-diabetic rats. Diabetologia 36, 299-304.

Cartmell J. and Schoepp D. D. (2000) Regulation of neurotransmitter release by metabotropic glutamate receptors. J. Neurochem. 75, 889-907.

Chatterjee S., Noack H., Possel H., Keilhoff G. and Wolf G. (1999) Glutathione levels in primary glial cultures: monochlorobimane provides evidence of cell type-specific distribution. Glia 27, 152161.

Cowell R. M. and Russell J. W. (2004) Peripheral neuropathy and the Schwann cell, in Neuroglia (Kettenmann H. and Ransom B. R., eds), pp. 573-585. Oxford University Press, Oxford.

van Dam P. S., Van Asbeck B. S., Erkelens D. W., Marx J. J., Gispen W. H. and Bravenboer B. (1995) The role of oxidative stress in neuropathy and other diabetic complications. Diabetes Metab. Rev. 11, 181-192.

van Dam P. S., Van Asbeck B. S., Bravenboer B., Van Oirschot J. F., Gispen W. H. and Marx J. J. (1998) Nerve function and oxidative stress in diabetic and vitamin E-deficient rats. Free Radic. Biol. Med. 24, 18-26.

van Dam P. S., Van Asbeck B. S., Bravenboer B., Van Oirschot J. F., Marx J. J. and Gispen W. H. (1999) Nerve conduction and antioxidant levels in experimentally diabetic rats: effects of streptozotocin dose and diabetes duration. Metabolism 48, 442-447.

van Dam P. S., Van Asbeck B. S., Van Oirschot J. F., Biessels G. J., Hamers F. P. and Marx J. J. (2001) Glutathione and alpha-lipoate in diabetic rats: nerve function, blood flow and oxidative state. Eur. J. Clin. Invest. 31, 417-424.

De Blasi A., Conn P. J., Pin J. and Nicoletti F. (2001) Molecular determinants of metabotropic glutamate receptor signaling. Trends Pharmacol. Sci. 22, 114-120.

Delaney C. L., Russell J. W., Cheng H.-L. and Feldman E. L. (2001) Insulin-like growth factor-I and over-expression of $\mathrm{Bcl}-\mathrm{xL}$ prevent glucose-mediated apoptosis in Schwann cells. J. Neuropathol. Exp. Neurol. 60, 147-160.

Deng W., Wang H., Rosenberg P. A., Volpe J. J. and Jensen F. E. (2004) Role of metabotropic glutamate receptors in oligodendrocyte excitotoxicity and oxidative stress. Proc. Natl Acad. Sci. USA 101, $7751-7756$.

Dringen R., Pfeiffer B. and Hamprecht B. (1999) Synthesis of the antioxidant glutathione in neurons: supply by astrocytes of CysGly as precursor for neuronal glutathione. J. Neurosci. 19, 562-569.

Dringen R., Gutterer J. M. and Hirrlinger J. (2000) Glutathione metabolism in brain metabolic interaction between astrocytes and neurons in the defense against reactive oxygen species. Eur. J. Biochem. 267, 4912-4916.

Dyck P. J., Kratz K. M., Karnes J. L., Litchy W. J., Klein R., Pach J. M., Wilson D. M., O’Brien P. C. and Melton L. J. III (1993) The prevalence by staged severity of various types of diabetic neuropathy, retinopathy, and nephropathy in a population-based cohort: The Rochester Diabetic Neuropathy Study. Neurology 43, 817824. 
Fernandez-Checa J. C. and Kaplowitz N. (1990) The use of monochlorobimane to determine hepatic GSH levels and synthesis. Anal. Biochem. 190, 212-219.

Fujimura M., Morita-Fujimura Y., Kawase M., Copin J. C., Calagui B., Epstein C. J. and Chan P. H. (1999) Manganese superoxide dismutase mediates the early release of mitochondrial cytochrome $\mathrm{C}$ and subsequent DNA fragmentation after permanent focal cerebral ischemia in mice. J. Neurosci. 19, 3414-3422.

Gegg M. E., Clark J. B. and Heales S. J. (2005) Co-culture of neurones with glutathione deficient astrocytes leads to increased neuronal susceptibility to nitric oxide and increased glutamate-cysteine ligase activity. Brain Res. 1036, 1-6.

Ghezzi P., Bonetto V. and Fratelli M. (2005) Thiol-disulfide balance: from the concept of oxidative stress to that of redox regulation. Antioxid. Redox Signal. 7, 964-972.

Gil-del Valle L., de la C. M., Toledo A., Vilaro N., Tapanes R. and Otero M. A. (2005) Altered redox status in patients with diabetes mellitus type I. Pharmacol. Res. 51, 375-380.

Halliwell B. (2000) The antioxidant paradox. Lancet 355, 1179-1180.

Halliwell B. (2003) Oxidative stress in cell culture: an under-appreciated problem? FEBS Lett. 540, 3-6.

Hohman T. C., Banis D., Basso M., Cotter M. A. and Cameron N. E. (1997) Resistance to increased oxidative stress is decreased in experimental diabetic neuropathy. J. Peripher. Nerv. Syst. 2, 272.

Hua Long L. and Halliwell B. (2001) Oxidation and generation of hydrogen peroxide by thiol compounds in commonly used cell culture media. Biochem. Biophys. Res. Commun. 286, 991-994.

Huang T. J., Price S. A., Chilton L., Calcutt N. A., Tomlinson D. R., Verkhratsky A. and Fernyhough P. (2003) Insulin prevents depolarization of the mitochondrial inner membrane in sensory neurons of type 1 diabetic rats in the presence of sustained hyperglycemia. Diabetes 52, 2129-2136.

Keelan J., Allen N. J., Antcliffe D., Pal S. and Duchen M. R. (2001) Quantitative imaging of glutathione in hippocampal neurons and glia in culture using monochlorobimane. J. Neurosci. Res. 66, 873884.

Kishi M., Tanabe J., Schmelzer J. D. and Low P. A. (2002) Morphometry of dorsal root ganglion in chronic experimental diabetic neuropathy. Diabetes 51, 819-824.

Lin S. H. and Maiese K. (2001) The metabotropic glutamate receptor system protects against ischemic free radical programmed cell death in rat brain endothelial cells. J. Cereb. Blood Flow Metab. 21, 262-275.

Low P. A., Nickander K. K. and Tritschler H. J. (1997) The roles of oxidative stress and antioxidant treatment in experimental diabetic neuropathy. Diabetes 46(Suppl. 2), S38-S42.

Maiese K. and Vincent A. M. (1999) Group I metabotropic receptors down-regulate nitric oxide induced caspase- 3 activity in rat hippocampal neurons. Neurosci. Lett. 264, 17-20.

Maiese K., Vincent A., Lin S. H. and Shaw T. (2000) Group I and group III metabotropic glutamate receptor subtypes provide enhanced neuroprotection. J. Neurosci. Res. 62, 257-272.

Maritim A. C., Sanders R. A. and Watkins J. B. III (2003) Diabetes, oxidative stress, and antioxidants: a review. J. Biochem. Mol. Toxicol. 17, 24-38.

Melendez R. I., Vuthiganon J. and Kalivas P. W. (2005) Regulation of extracellular glutamate in the prefrontal cortex: focus on the cystine glutamate exchanger and group I metabotropic glutamate receptors. J. Pharmacol. Exp. Ther. 314, 139-147.

Moran M. M., McFarland K., Melendez R. I., Kalivas P. W. and Seamans J. K. (2005) Cystine/glutamate exchange regulates metabotropic glutamate receptor presynaptic inhibition of excitatory transmission and vulnerability to cocaine seeking. J. Neurosci. 25, 6389-6393.
Nagamatsu M., Nickander K. K., Schmelzer J. D., Raya A., Wittrock D. A., Trischler H. and Low P. A. (1995) Lipoic acid improves nerve blood flow, reduces oxidative stress, and improves distal nerve conduction in experimental diabetic neuropathy. Diabetes Care 18, 1160-1167.

Niedowicz D. M. and Daleke D. L. (2005) The role of oxidative stress in diabetic complications. Cell. Biochem. Biophys. 43, 289-330.

Obrosova I. G. (2002) How does glucose generate oxidative stress in peripheral nerve? Int. Rev. Neurobiol. 50, 3-35.

Pizzi M., Benarese M., Boroni F., Goffi F., Valerio A. and Spano P. F. (2000) Neuroprotection by metabotropic glutamate receptor agonists on kainate-induced degeneration of motor neurons in spinal cord slices from adult rat. Neuropharmacology 39, 903-910.

Rice M. E. and Russo-Menna I. (1998) Differential compartmentalization of brain ascorbate and glutathione between neurons and glia. Neuroscience 82, 1213-1223.

Russell J. W. and Feldman E. L. (1999) Insulin-like growth factor-I prevents apoptosis in sympathetic neurons exposed to high glucose. Horm. Metab. Res. 31, 90-96.

Russell J. W. and Kaminsky A. J. (2005) Oxidative injury in diabetic neuropathy, in Nutrition and Diabetes: Pathophysiology and Management (Opara E., ed.), pp. 381-397. Taylor \& Francis, Boca Raton, FL.

Russell J. W., Sullivan K. A., Windebank A. J., Herrmann D. N. and Feldman E. L. (1999) Neurons undergo apoptosis in animal and cell culture models of diabetes. Neurobiol. Dis. 6, 347-363.

Russell J. W., Golovoy D., Vincent A. M., Mahendru P., Olzmann J. A., Mentzer A. and Feldman E. L. (2002) High glucose-induced oxidative stress and mitochondrial dysfunction in neurons. FASEB J. 16, 1738-1748.

Sagara J. I., Miura K. and Bannai S. (1993) Maintenance of neuronal glutathione by glial cells. J. Neurochem. 61, 1672-1676.

Sasaki H., Schmelzer J. D., Zollman P. J. and Low P. A. (1997) Neuropathology and blood flow of nerve, spinal roots and dorsal root ganglia in longstanding diabetic rats. Acta Neuropathol. 93, $118-128$.

Schmeichel A. M., Schmelzer J. D. and Low P. A. (2003) Oxidative injury and apoptosis of dorsal root ganglion neurons in chronic experimental diabetic neuropathy. Diabetes 52, 165-171.

Schoepp D. D., Jane D. E. and Monn J. A. (1999) Pharmacological agents acting at subtypes of metabotropic glutamate receptors. Neuropharmacology 38, 1431-1476.

Sebastia J., Cristofol R., Martin M., Rodriguez-Farre E. and Sanfeliu C. (2003) Evaluation of fluorescent dyes for measuring intracellular glutathione content in primary cultures of human neurons and neuroblastoma SH-SY5Y. Cytometry A 51, 16-25.

Srinivasan S., Stevens M. J. and Wiley J. W. (2000) Diabetic peripheral neuropathy: evidence for apoptosis and associated mitochondrial dysfunction. Diabetes 49, 1932-1938.

Stevens M. J., Obrosova I., Cao X., Van Huysen C. and Greene D. A. (2000) Effects of DL-alpha-lipoic acid on peripheral nerve conduction, blood flow, energy metabolism, and oxidative stress in experimental diabetic neuropathy. Diabetes 49, 1006-1015.

Suzuki T., Sekido H., Kato N., Nakayama Y. and Yabe-Nishimura C. (2004) Neurotrophin-3-induced production of nerve growth factor is suppressed in Schwann cells exposed to high glucose: involvement of the polyol pathway. J. Neurochem. 91, 1430-1438.

Tachi Y., Okuda Y., Bannai C., Okamura N., Bannai S. and Yamashita K. (1998) High concentration of glucose causes impairment of the function of the glutathione redox cycle in human vascular smooth muscle cells. FEBS Lett. 421, 19-22.

Tang X. C. and Kalivas P. W. (2003) Bidirectional modulation of cystine/ glutamate exchanger activity in cultured cortical astrocytes. Ann. N. Y. Acad. Sci. 1003, 472-475. 
Thomas A. G., Vornov J. J., Olkowski J. L., Merion A. T. and Slusher B. S. (2000) $N$-Acetylated alpha-linked acidic dipeptidase converts $\mathrm{N}$-acetylaspartylglutamate from a neuroprotectant to a neurotoxin. J. Pharmacol. Exp. Ther. 295, 16-22.

Thomas A. G., Olkowski J. L. and Slusher B. S. (2001) Neuroprotection afforded by NAAG and NAALADase inhibition requires glial cells and metabotropic glutamate receptor activation. Eur. J. Pharmacol. 426, 35-38.

Thomas A. G., Corse A. M., Coccia C. F., Bilak M. M., Rothstein J. D. and Slusher B. S. (2003) NAALADase inhibition protects motor neurons against chronic glutamate toxicity. Eur. J. Pharmacol. 471, $177-184$.

Tomlinson D. R. (1998) Future prevention and treatment of diabetic neuropathy. Diabetes Metab. 24(Suppl. 3), 79-83.

Vincent A. M. and Maiese K. (2000) The metabotropic glutamate system promotes neuronal survival through distinct pathways of programmed cell death. Exp. Neurol. 166, 65-82.

Vincent A. M., Mohammad Y., Ahmad I., Greenberg R. and Maiese K. (1997) Metabotropic glutamate receptors prevent nitric oxideinduced programmed cell death. J. Neurosci. Res. 50, 549-564.

Vincent A. M., Brownlee M. and Russell J. W. (2002) Oxidative stress and programmed cell death in diabetic neuropathy. Ann. N. Y. Acad. Sci. 959, 368-383.

Vincent A. M., Olzmann J. A., Brownlee M., Sivitz W. I. and Russell J. W. (2004a) Uncoupling proteins prevent glucose-induced neuronal oxidative stress and programmed cell death. Diabetes 53, 726-734.
Vincent A. M., Russell J. W., Low P. and Feldman E. L. (2004b) Oxidative stress in the pathogenesis of diabetic neuropathy. Endocr. Rev. 25, 612-628.

Wroblewska B., Wroblewski J. T., Saab O. H. and Neale J. H. (1993) $\mathrm{N}$-Acetylaspartylglutamate inhibits forskolin-stimulated cyclic AMP levels via a metabotropic glutamate receptor in cultured cerebellar granule cells. J. Neurochem. 61, 943-948.

Wroblewska B., Wroblewski J. T., Pshenichkin S., Surin A., Sullivan S. E. and Neale J. H. (1997) $N$-Acetylaspartylglutamate selectively activates mGluR3 receptors in transfected cells. J. Neurochem. $\mathbf{6 9}$, 174-181.

Xi Z. X., Baker D. A., Shen H., Carson D. S. and Kalivas P. W. (2002) Group II metabotropic glutamate receptors modulate extracellular glutamate in the nucleus accumbens. J. Pharmacol. Exp. Ther. 300, $162-171$.

Yao H. H., Ding J. H., Zhou F., Wang F., Hu L. F., Sun T. and Hu G. (2005) Enhancement of glutamate uptake mediates the neuroprotection exerted by activating group II or III metabotropic glutamate receptors on astrocytes. J. Neurochem. 92, 948-961.

Zhang W., Slusher B., Murakawa Y., Wozniak K. M., Tsukamoto T., Jackson P. F. and Sima A. A. (2002) GCPII (NAALADase) inhibition prevents long-term diabetic neuropathy in type 1 diabetic BB/Wor rats. J. Neurol. Sci. 194, 21-28.

Zhong C., Zhao X., Sarva J., Kozikowski A., Neale J. H. and Lyeth B. G. (2005) NAAG peptidase inhibitor reduces acute neuronal degeneration and astrocyte damage following lateral fluid percussion TBI in rats. J. Neurotrauma 22, 266-276. 